\title{
Consequences of HIV Infection on Household Assets and Human Capital Investment in Uganda: Micro Evidence
}

\author{
Buyinza Faisal $^{1}$, Teera Joweria ${ }^{1} \&$ Bateganya Fred Henry ${ }^{2}$ \\ ${ }^{1}$ School of Economics, Makerere University, Uganda \\ ${ }^{2}$ Department of Sociology and Anthropology, Makerere University, Uganda \\ Correspondence: Buyinza Faisal, School of Economics, Makerere University, Uganda. E-mail: \\ bbkfaisal@gmail.com
}

Received: December 7, 2015

Accepted: April 25, 2016

Online Published: November 20, 2017

doi:10.5539/ijef.v9n12p202

URL: https://doi.org/10.5539/ijef.v9n12p202

\begin{abstract}
This paper studies the effect of the HIV and AIDS epidemic on economic decision making using the Uganda National Household Survey (2010). The findings indicate that household's HIV and AIDS status, education and social-economic factors are important in explaining low household's asset accumulation and school enrolments of children in Uganda especially at primary school level. Household savings and assets accumulation findings show that household's HIV and AIDS status and their education levels, marital status and the employment status are consistently associated with lower savings. Major implications of these results is that raising women's education improves their economic opportunities and the behavioral responses in sexual interaction will lead to decline in HIV infection by reducing the willingness to engage in unprotected sex. In fact, we find that educational performance declines in those HIV infected households in which the father is living with HIV. The paper recognizes the policy challenges surrounding the HIV and AIDS -education linkage and considers some of the strategies that have been implemented to improve the schooling outcomes of children from households of people living with HIV (PLHIV). We find a weak positive effect of HIV infection on savings and a significant positive effect on school enrolment and educational expenses for children. High-perceived infection risk has a positive albeit imprecise influence on school enrollment and educational expenses, but no effect on savings.
\end{abstract}

Keywords: HIV infection, household saving, asset accumulation and education

\section{Introduction}

The HIV and AIDS epidemic is a global concern of every country in the world, though it is a greater concern in most African countries where HIV infection seems to increase despite prevention and treatment interventions. Coupled with other socio economic and political problems such as poverty, high fertility, low literacy and, the incidence of HIV infection in Uganda, like in many other African countries, HIV and AIDS continues to be serious a challenge both at national and household levels. It is noted, however, that rural households are the most affected partly due to poor or lack of service delivery. Poku (2005) found that HIV and AIDS is costly to most households and communities. During periods of illness, medical costs rise, work and incomes are disrupted, family members are withdrawn from work to provide care and, in some instances, children have to work to supplement household incomes.

There are over 40 million people living with HIV (PLHIV) globally, 24.7 million (71\% of the global figure) of whom in SSA (UNAIDS; 2015). UNAIDS (2002) notes that more than 60 million people have been infected with HIV and a little over 20 million have died of AIDS since the first clinical evidence of HIV/AIDS was reported in 1981. HIV and AIDS related illnesses is by far the leading cause of death in Sub Saharan Africa (SSA), and the fourth biggest globally (WHO, 2002). While SSA has the most PLHIV in the world, it is home to only $9 \%$ of the world's population (Caldwell et al., 2002). Most people suffering from AIDS are found in countries of the AIDS belt. Caldwell (2002) argues that the AIDS belt stretches from Central African Republic and Southern Sudan through Uganda, Rwanda, Burundi, Kenya and Tanzania to Malawi, Zambia, Zimbabwe, Botswana, South Africa and Namibia.

While the devastating effects of AIDS on socio-economic and demographic outcomes are widely acknowledged, little is known about how the epidemic influences households' inter-temporal choices to cope with the increased health and financial risks in Uganda. The epidemic not only changes the choices that PLHIV households make 
over time, it might also influence the behavior of unaffected households. The findings of the economic impact on households are similar in most studies (Greener, 2002; Poku, 2005; Weiss, 1993; UNAIDS, 2000), indicating that HIV and AIDS imposes serious financial burden on families, societies, nations, continent and the world at large.

This paper aims at examining the effect of households' HIV and AIDS status on saving/asset accumulation decisions and human capital investment, which are both strategies to transfer present consumption to the future at positive expected returns. We analyze whether HIV status and perceptions of HIV infection risk induce anticipatory behavior with respect to savings and human capital investment. A better understanding of this issue will provide policy makers the information they need to decide whether to change the existing health status in the country. The decreased life expectancy reduces the future benefits of capital investments while both the risk of severe and long-term illness as well as a bequest motives do enhance the transfer of current consumption to the future.

To meet the objectives of this study, the study focuses on three specific objectives. First, we examine the impact of household HIV status and other social-economic factors on household assets. Second, we examine whether household HIV status negatively affects the school performance of children. Despite the importance of understanding how HIV and AIDS status affects household assets and child development, rigorous empirical research on this topic remains relatively limited in Uganda.

To achieve the study objective, we analyzed household saving and investments behaviour in Uganda using micro data from the Uganda National Households Survey (UBOS, 2009/10) collected by Uganda Bureau of Statistics, which includes extensive socio-economic data as well as direct HIV screening results. The study sought to answer the following pertinent questions: Does HIV infection decrease households' savings and school enrolment and educational expenses for children? What is the effect of high-perceived HIV infection risk on school enrollment and educational expenses and savings? Answers to these questions will guide informed policy discussions that can improve government in mitigating the economic impacts of HIV and AIDS on households. To that end, a conventional Probit model was employed for the estimation of household savings decision and a typical OLS regression corrected for selectivity bias used for the estimation of the human capital investment equation.

This paper empirically investigated how the risk of HIV infection affects household decisions on saving behavior and human capital investments in Uganda. The outcome of HIV infection on household decision depends on at least two main opposing effects of the risk of HIV infection. On the one hand, the AIDS epidemic decreases the life expectancy, which in turn reduces lifetime benefits of capital investments by reducing individual and community productivity. Thus, it will exert a negative influence on current investment decisions. On the other hand, households may adopt coping strategies in anticipation of future illness. These could be in form of increasing expectations of high medical expenditures, home health care, higher nutritional needs or reduction in future income-generating possibilities related to HIV and AIDS, children and adult trauma and stigma among others all which influence overall household behavior.

At the level of the household, AIDS results in the loss of income, assets, savings and an increase in spending on health care by the households. HIV and AIDS epidemic slows down the pace of economic growth.

Men and women tend to own assets and money separately, and tend to have separate income earning activities. Yet because care giving usually falls on women, it appears that the rise of prolonged sickness and care due to AIDS related illnesses has reduced the time available for women to engage in income-earning activities more so than for men (Opiyo, 2001), and this trend is likely to become even more pronounced in future decades in the hardest-hit households as the casualties of the disease escalate. Arndt et al. (2001) and Yamano and Jayne (2004) found that households suffering the death of head-of-household or spouse were largely unable to replace the labour lost through the death, whereas households suffering the death of another adult (other than the head or spouse) were largely able to attract new household members. This at least partially stabilizes the supply of family labour for agriculture, but implies that off-farm and remittance incomes may in some cases be reduced, exacerbating capital constraints in agriculture.

While health improvements can promote virtuous development spirals, health shocks can set off vicious spirals. HIV and AIDS is reducing life expectancy in many African countries by up to 30 years. Based on estimates in the literature of the link from life expectancy to economic growth (Bloom \& Canning, 2000), AIDS in Africa has the potential to consume two percentage points of economic growth. With average annual growth rates of real per capita income in most of Sub-Saharan Africa ranging from -2 percent to 3 percent, the damage will be significant. Other health problems can also impede growth. For example, Gallup and Sachs report that countries 
with high levels of malaria have much lower levels of income, even after controlling for potentially confounding factors. Health, therefore, poses a complex and pressing series of challenges for individuals and governments. Major shifts in health status are sometimes built on the same foundations as economic growth-new knowledge and technology, new investment, and new labour structures.

Our empirical results reveal that the presence of HIV and AIDS has a negative economic impact on households with members infected by HIV and AIDS. These economic impacts include those on households' income, savings, expenditure, assets and lending. Also our findings indicate that age and education background are important factors in household asset accumulation and education of the children in an HIV and AIDS infected household. In addition, marital status has a strong influence on household assets in case members are infected with HIV and AIDS compared to the never married category. The results of this paper contribute not only to the body of knowledge on the impact of HIV epidemic on human capital investment by examining how children's education outcomes respond to the HIV infection of their parents or any other household member, but also inform policy makers and other stakeholders on the different impact of HIV and AIDS on children's education outcomes.

The reminder of the paper is structured as follows. The preceding section concentrated on the motivation of the paper and highlighting the debate found in the previous literature. Section two gives the theoretical framework and the estimation strategy. Section 3 presents a discussion of the main findings while Section 4 concludes the paper and highlights the paper's implications for policy.

\section{Methodology and Data}

\subsection{Study Methodology}

Figure 2 presents a conceptual framework that explored the pathways for HIV and AIDS effects on households' asset accumulation and human capital investments. The development of this framework was based on the results from the review of studies presented above. It includes relevant determinants and outcomes for household decision-making that ultimately affect household's asset accumulation and human capital investments. The study takes into account not only the direct effect on household's assets and income with HIV infection by the household head but HIV infection by any household members as well. These experiences are taken into account when a household with an HIV infected member decides on a course of action regarding use of the existing household wealth and human capital investments. Also, individual decisional esteem, a form of self-efficacy with regard to future resource utilisation and income generations decision making are considered. Thus, the HIV positive effects on household behaviour can be illustrated using Figure 1 below:

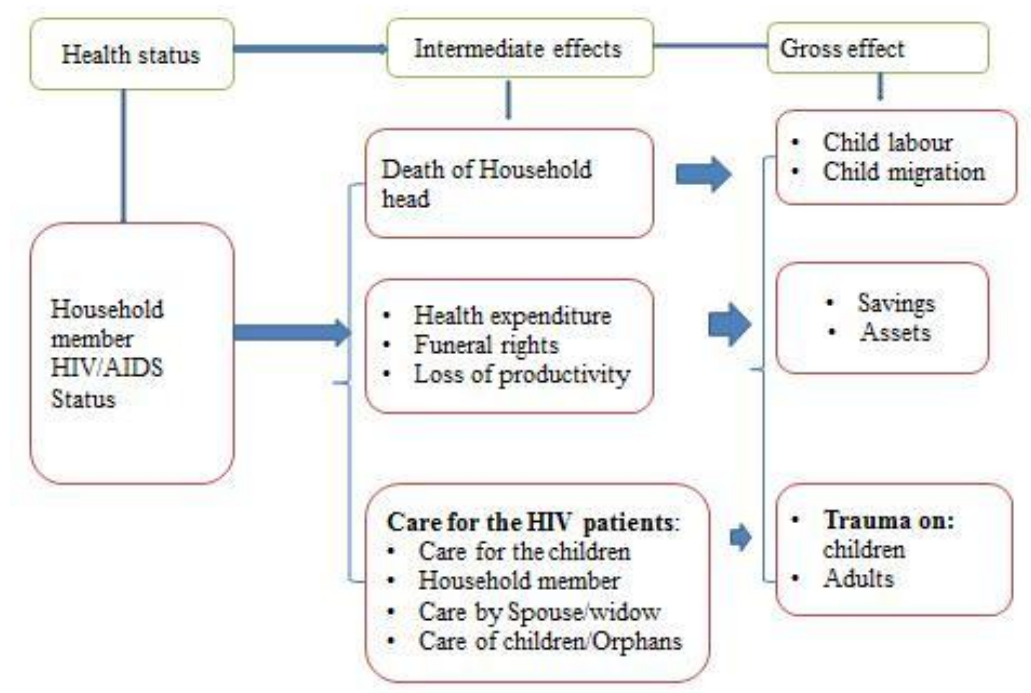

Figure 1. Impact of HIV and AIDS on household assets and human capital

Source: Authors construction from reviewed literature.

The conceptual framework (Figure 1) presents the gross impacts of HIV and AIDS on the household and it shows the chain of implications of the epidemic from the immediate impact of death of household head to the 
loss of wealth of the household plus the negative impact on human development. Apart from death of the household head, the members of the household living with HIV need care and this care cannot be negotiated or planned. Having an HIV infected person will result in loss of household productivity that is likely to affect the wealth of the household. The terminal change in the wealth of the household is then called the net impact.

From Figure 1, the health expenditures and funeral costs are "direct costs", whereas loss of income due to the fall in productivity of the members living with HIV is an "indirect cost". Health expenditures include medical care and transport costs and this could represent a significant percentage of the household income of HIV and AIDS affected households. For the funeral costs, HIV and AIDS does not change this value, given that everyone will die one day. The HIV and AIDS implicit cost relates to the repetition of funeral costs or participation in funeral costs. Also, the deceased passed away sooner than in the absence of the epidemic, and the sooner the death occurs, the less time to save for funeral costs, the higher the relative cost of funeral.

The gross impact in terms of income are higher if the head of the household is infected with HIV than for other members, for a worker than for an unemployed member, for a young person than for an elderly one, for an adult than for a child. Also, our conceptual framework highlights how HIV infection impacts concern the care of the members living with HIV and AIDS by other members, while they are still alive, and the care of their nuclear family by other individuals during their illness and after their death. In addition, concerning care given at home, an adult who stops working significantly lowers the financial wealth of the household in the short run, whereas when a child is withdrawn from school the human wealth of the household in the long run is negatively affected. The economic impact of trauma on adults and children refers to the undetermined effect of the disease on the motivation to cumulate financial wealth in the case of an adult and human capital wealth in the case of children in an environment of illness and death.

Basically, these impacts will depend on the relationship of the members living with HIV with the other members. The resultants effect to the children may include migration, child labour, and school dropout and child trauma. HIV infection could also result into sale of assets, use of savings as the household seek for treatment. Generally, household members living in a household with PLHIV are bound to change. First, the members living with HIV and AIDS themselves will change from the status of a productive or active member to one of being ill and finally deceased. Secondly, other members of affected households will anticipate the expenditures due to morbidity as well as mortality and change their vision of the future, hence change their economic behaviour incorporating potential future costs and a potential reduction of their productive lives. Chronically, members of affected households will change in status into care givers, orphans or widows.

\subsection{The Model}

To understand the impact of household's HIV and AIDS status and household's savings and asset accumulation in Uganda, first, household asset/savings model (Equation 1) is estimated to examine the impact of HIV and AIDS and other determinants of household savings in Uganda.

Generally, in the case of HIV infection of the household member, it is assumed that a household may choose to save or accumulate assets in order to ensure against the expected loss of future earnings and increased medical expenditures among others. On the other hand, household may choose not to save or accumulate assets like cows, land, goats or keep cash in the house, and to the worst a household that does not make any savings in assets hence the household will not make any savings rather it could de-accumulate its assets. Therefore, to examine the impact of having HIV by households on household savings or asset accumulation, we estimate the following savings model:

$$
S A_{i}=\beta_{0}+\beta_{1} H I V_{i}+\beta_{2} E_{d u c_{i}}+\beta_{3} H S_{i}+\beta_{4} \text { Emp }_{i}+\beta_{5} \text { Sex }_{i}+\beta_{6} \text { Age }_{i}+\beta_{7} \text { region }_{i}+\varepsilon_{i}
$$

From Equation 1, SA denotes household savings/asset and is a continuous dependent variable, while the household HIV and AIDS status is a binary variable recorded 1 if the household has an HIV infected member and 0 otherwise. The variable educ is a measure of household head's education level in both rural and urban areas while $H S$ is household size, Emp is employment status of household head, Sex is gender of household head, Age is age of household head, rel is religious belief and region is region of residence, among others. The last term $\varepsilon$, is a normally distributed error term.

To examine the impact of household HIV and AIDS status on the human capital development, we characterize educational enrollment for the $i^{\text {th }}$ child in a given household by the following binary Probit model:

$$
\text { enrol }_{i}=\beta_{0}+\beta_{1} \text { hhmig }_{i}+\beta_{2} X_{i}+\beta_{3} F_{i}+\varepsilon_{i}
$$


From Equation 2, our main variable of interest is the migrant household status ( hhmig). The set of control variables $X$ include the sample child's and parent's characteristics. The samples used in the probit regressions include children from the same household; it is possible that unobservable household specific characteristics determining school enrolment are correlated among children of the same household. To overcome this problem, we use the cluster estimation techniques to obtain the total effect of migration on enrolment. In addition, we control for households' wealth and land holding, as well as parental occupations, to examine the existence of wealth effects.

\subsection{Data}

The study used data sets of thee 2009/10 Uganda national household survey (UNHS) collected by the Uganda Bureau of Statistics. The UNHS was a multipurpose survey designed with three modules, namely, socioeconomic survey, community survey, and agriculture survey. Apart from the standard socio-economic information the socioeconomic survey probed households on the household health status relating to the HIV infections, HIV and AIDS perceived risks and various forms of savings and change in household assets over the five-year period preceding the survey.

Information from this section was merged with other sections and modules to identify the socio-economic, community and other determinants of the choice of a particular existing health and education institutions. The community survey was designed to collect data on the characteristics of local council one area (LC 1), demographic information relating to communities residing in the sampled enumeration areas (EA) and various details on economic and social infrastructure in those areas. To facilitate meaningful transformation of the data, efforts were made to clean the data by checking for duplicates, inconsistencies and outliers. Sampling weights were used throughout the analysis to account for over- and under-sampling in various enumeration areas, making the sample data nationally representative.

The household HIV status is defined as being HIV positive as equal to 1 and 0 otherwise. In addition, the HIV perceived risk is also defined as dummy variable being equal to 1 for high perceived risk and 0 otherwise. Also the household education status is defined varying between 1 and 5, representing 1 for no education and 5 for the highest education (graduate). The savings variables have been derived from the self-assessment; their value is equal to 1 if the household reported to have formal savings with a financial institution and 0 if no formal savings were reported. Also the asset variable in terms of change in asset accumulation between 2001 and 2010 was derived from the self-assessment of household members; their value is equal to - 1 if household assets in 2005 are less than in 2001, 0 if there is no change in assets and 1 if household assets in 2005/6 are more than 2001 assets.

We also include household age squared to examine the increasing effect of household size on household savings. The age of the household head has a significant positive relationship with household savings up to a certain maximum threshold. Increasing the age of the household head beyond this threshold starts to have significant negative effect relationship with household savings. Also we include the gender of the household members to capture the impact of microfinance institutions inclination to lending to women as opposed to men. As the literature provides, that women are more honesty and have a high repayment rate of their loans than their male counterparts. Thus, the gender of the borrowers is coded as equal to 1 for male borrowers and 0 otherwise. In addition, we include employment status of the household head whether is employed in regular income job or occasional employment. Also we examine whether the spouse is working or not. That is, when the spouse is employed, it is assigned the value of 1 and 0 otherwise. Furthermore, to capture the impact of microfinance institution of household ability to accumulate savings and assets, also we include distance to the nearest district market as a proxy for household market access.

\section{Results}

This section presents the findings of this study in view of the impact of HIV positive household status on the household's asset accumulation and human capital investments in Uganda. The first section focuses on the results obtained through descriptive analysis by tabulations and graphical presentation of the relationship between HIV infected household and the household savings and asset accumulation and human capital investments.

\subsection{Descriptive Evidence}

Further, we analyse the gender proportions of HIV infected headed households as can be observed on Figure 2 below. The analysis reveals that more male HIV infected headed households of 56.83 percent compared to 43.17 
percent of women. This result still implies that male HIV infected headed households are more than female HIV infected headed households, though the data could not enable us to analyse how men contract HIV.

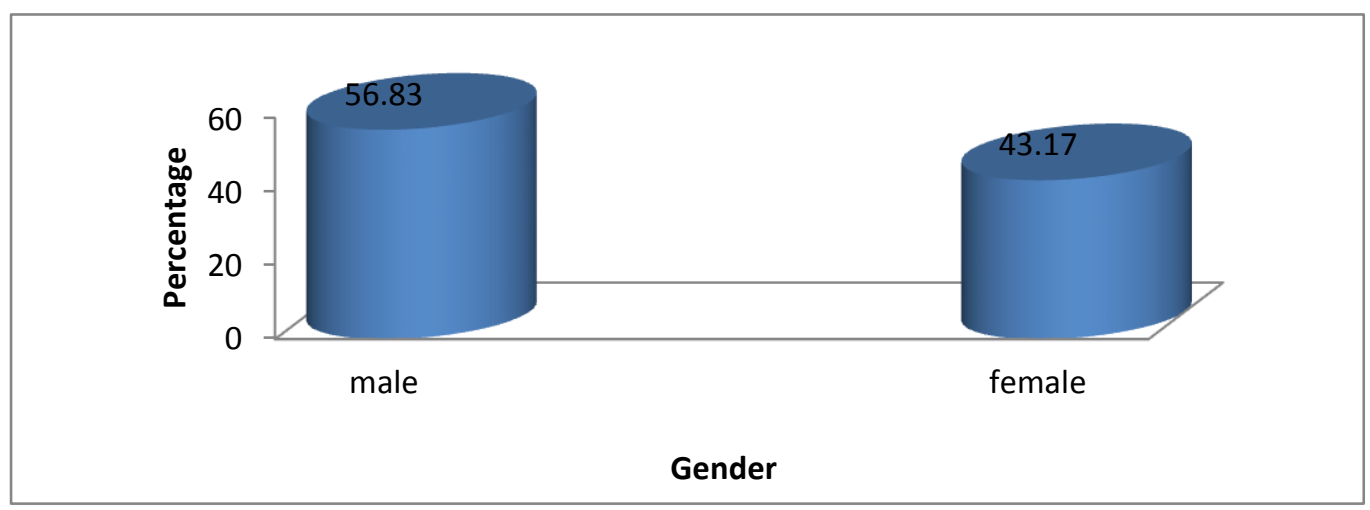

Figure 2. HIV infected headed households

Source: UNHS (2009/10).

Figure 3 presets that HIV infected hosueholds' assets category that was reported 2010 by gender. The questions in the survey probbed household respondents to assess the househod asset value and this in the analysis has been categorised into five groups as shown on Figure 3. The results indicate that in the high value asset categories, men dominate the women and it is only in the first category of the asset values ranging between Shs 1-10,000 where women are more than men with 37.23 percent.

Figure 3 also reveal interesting findings that indicate that many HIV infected households's asset values fall below Shs 500,000, which means with this asset value, which is too small to enable households do any feasible business and meet the increase household demands with the HIV epidemic. With most housholds having asset value falling below Shs 500,000, it means that with HIV infections, the household assets are likely to be eroded very soon.

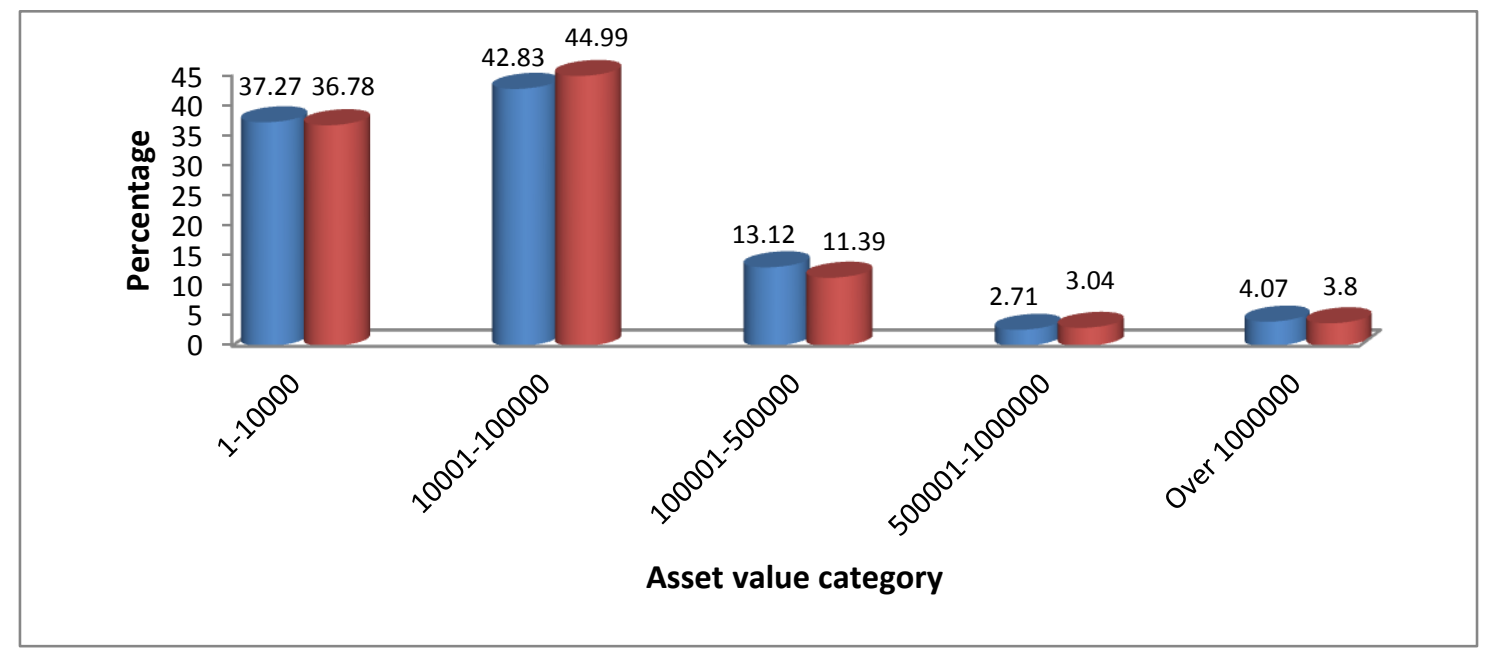

Figure 3. HIV infected households' asset ownership by gender

Source: UNHS (2009/10).

Table 1 presents the basic summary statistics of the households that have an HIV infected member. The results in Table 3 show that mean age of the women living in households that have an HIV infected person is 21.5 years while the mean age of men living in households that have an HIV infected person is 19.4 years. This implies women living in households that have an HIV infected person are older than men by about 2 years on average. 
In addition, on average, household asset value is Shs 812,021 for those living in households that have an HIV infected person. Also analysis of the amount of loans received by households living in households that have an HIV infected person and their spouse reveal that on average men received bigger loans of Shs 398,271 than women who received Shs 230,272. This indicates that on average men receive over Shs 120,000 more than women living in households that have an HIV infected person.

Table 1. Summary statistics for selected household features

\begin{tabular}{|c|c|c|c|}
\hline Variable & Mean & SD & $\mathrm{CV}$ \\
\hline \multicolumn{4}{|l|}{ Father's education: } \\
\hline Father primary education & 0.55 & 0.50 & 0.91 \\
\hline Father secondary education & 0.24 & 0.43 & 1.77 \\
\hline Father postsecondary & 0.03 & 0.18 & 5.26 \\
\hline \multicolumn{4}{|l|}{ Mother's education: } \\
\hline Father primary education & 0.51 & 0.50 & 0.98 \\
\hline Father secondary education & 0.07 & 0.26 & 3.60 \\
\hline Father postsecondary & 0.01 & 0.10 & 9.65 \\
\hline Women's age & 21.48 & 17.61 & 0.82 \\
\hline Men's age & 19.41 & 15.07 & 0.78 \\
\hline Household size & 6.01 & 3.02 & 0.50 \\
\hline Land size (acres) & 4.00 & 10.39 & 2.60 \\
\hline loan repayment period (months) & 8.08 & 15.55 & 1.92 \\
\hline Asset values (shs) & 812021.50 & 4802148.00 & 5.91 \\
\hline household head loan (shs) & 398271.70 & 790469.40 & 1.98 \\
\hline Spouse's loan (shs) & 230272.20 & 553561.90 & 2.40 \\
\hline
\end{tabular}

Source: Author's tabulation from UNHS (2009/2010).

Also covariance analysis presented in Table 1 indicates that father's secondary education living in households that have an HIV infected person has the highest education variation of 9.65 for mother's postsecondary education, followed by 3.60 for mother's secondary education and 1.77 for father's secondary education, followed by 3.52 , whereas the lowest variation of 0.91 for father's primary education. This result point out the women are relatively less educated in households that have an HIV infected person compared to the male counterparts.

\subsection{Impact of HIV and AIDS on Household Saving Decisions}

Table 2 presents estimated effects of household HIV infection status on household's savings and assets for the empirical model outlined in Equation 1 and the results reinforce the expectation of the variables in the model. Most of the variables have the expected signs and are statistically significant at the conventional level. The empirical results regarding the impact of HIV infected status on household's savings and assets model are consistent with existing findings.

As expected our results for households' propensity to save (model 1) as well as their per capita saving levels (model 2) shows that neither an HIV infected status of the household head nor a high-perceived risk of HIV infection significantly reduces the propensity to save. That is, household marginal propensity to save for the HIV infected status households is 0.246 while the per capita savings is 0.069 basis points. In addition, the empirical results indicate that the propensity to accumulate assets is positive and statistically significant at $5 \%$ level (model 3). This finding implies that there is need for policy makers to empower households in terms of income generating capacity especially those infected with the HIV epidemic. In the case when a member of the household is HIV infected, the household propensity to save and per capita saving will reduce significantly by 0.016 and 0.022 basis points. This could be attributed to the medical expenditures and also time diverted to caring for the sick household member. However, in the case of no HIV infection by the household members, the propensity to save and per capita savings reduces by 0.033 and 0.011 basis points. Furthermore, theory suggests that high perceptions of individual HIV infection risk would also increase savings, however this is not observed in our empirical results. This finding is in line with the findings of Van de Kuilen and Lammers (2007) who revealed higher level of savings among respondents with a high-perceived risk of contracting HIV. 
Table 2. Estimation of impact of household's HIV status on savings and asset

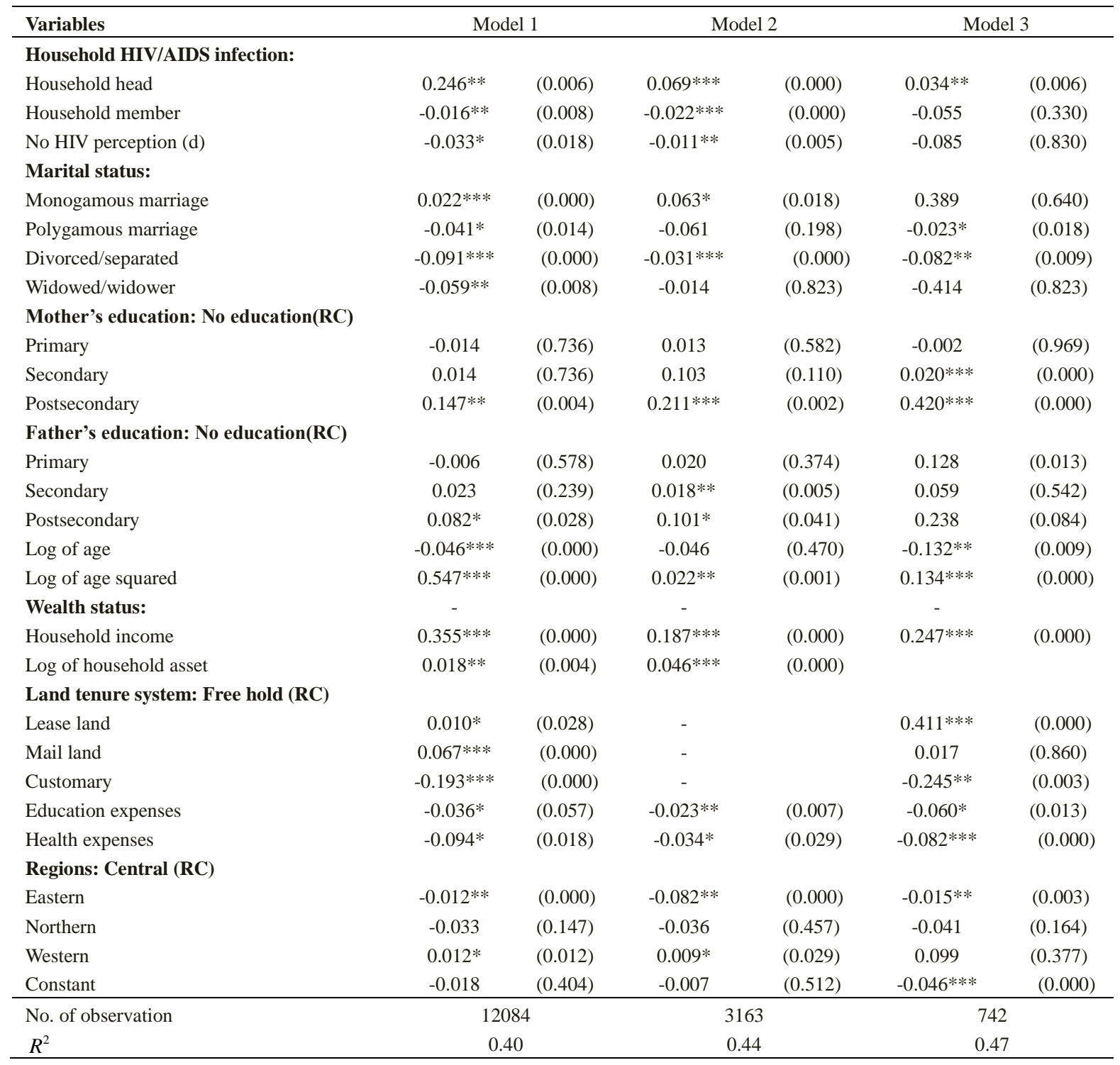

The P-values are given in parenthesis $(* \mathrm{p}<0.1, * * \mathrm{p}<0.05$, *** $\mathrm{p}<0.01)$.

In regard to the HIV infected household status, the results indicate that a monogamous married household increases the likelihood of household marginal propensity to save by 0.022 basis points and the per capita savings by 0.063 basis points, while asset by a factor of 0.089 units holding other variables constant. In addition, HIV infected household polygamous household decreases the likelihood of household savings and assets by a factor ranging between 0.041 and 0.023 respectively. Also our results reveal that an HIV infected household with separated and divorced parents or divorced decreases the propensity to save by 0.091 and 0.059 basis points respectively. The household's per capita savings for the separated HIV infected households reduces by 0.031 and their asset accumulation by a factor of 0.082 . Therefore, it is important for government to design measures that specifically target divorced HIV couples and the widows against the HIV devastating effects.

Table 2 results show that the effects of father's education and mother's education may have different magnitudes on HIV infected households' savings and assets accumulation. The results show that father's secondary education that is living with HIV will significantly impacts household asset accumulation. The coefficient on the only father is HIV infected household is positive and statistically significant at $1 \%$ level, indicating that father's secondary education increases the chances of household asset accumulation by 0.02 basis points. In addition, father's postsecondary education increases household propensity to save by 0.147 , the per capita savings by 0.021 and asset accumulation by 0.421 basis points. This suggests that HIV affected households anticipate not only medical expenditures but also lower future income-generating possibilities. Furthermore, our results 
indicate that mother's secondary education increases the chances of household propensity to save by 0.023 basis points and the per capita savings by 0.0180 .02 basis points. Also, mother's postsecondary education significantly increases household propensity to save and per capita savings by 0.082 and 0.101 basis points respectively.

Also, our results indicate significance of the age of the household head on household savings and asset accumulation. The estimated impact of the age of the household indicates that when the household head is young, this reduces household propensity to save by 0.046 basis points and the asset accumulation by 0.132 basis points. However, the coefficient of age squared is positive and statistically significant for all the three estimated models. This result implies that after a certain age threshold, household head focus on building households savings and assets. Looking the impact of wealth status in terms of household income increases household's propensity to save by 0.355 basis points, per capita savings by 0.187 units and the asset accumulation by 0.247 basis points. In addition, household assets affect households' propensity to save and per capita savings by 0.018 and 0.046 basis points respectively.

Furthermore, our results indicate significance of land ownership by the HIV infected household on household savings and asset accumulation. When an HIV infected household's land ownership is on a lease basis compared to counterparts that own free hold, this increases the household propensity to save by 0.01 basis points, while when household land is owned on the basis of mail land, this increases household's propensity to save by 0.067 basis points. However, customary land ownership has a negative significant effect on household propensity to save. In addition, if HIV infected household owns land based on lease tenure system this increases the household asset accumulation by 0.411 basis points, while customary land ownership decreases household asset accumulation by 0.245 basis points. This result indicate the importance of land registration that enable households to have land titles which they can use as security to process bank loans and thereby be able to undertake income generating activities. Therefore, there need for government to easy the process of land registration and getting titles as this increase the land value to the households.

Our results indicate significance of total educational expenditures on the household savings/assets of the HIV positive households. The estimated results indicate that the educational expenditures reduces household propensity to save by 0.039 and the per capita savings by 0.023 basis points. The impact of education expenses on household asset accumulation reduces by 0.06 basis points if the parents are HIV infected compared to their counterparts, other factor remaining constant. In addition, the estimated results indicate that the health expenditures significantly reduces household propensity to save by 0.094 and the per capita savings by 0.034 basis points. The impact of health expenses on household asset accumulation reduces by 0.082 basis points if the parents are HIV infected compared to their counterparts, other factor remaining constant.

In addition, household's savings and asset accumulation are divergent in the different regions in the country. First, the results indicate that household savings are negative and significantly correlated with household HIV positive status in the eastern region by about 0.082 basis points and the asset accumulation by 0.015 basis points. Our findings indicate that in the western region, households' per capita saving increases by 0.009 basis points compared to their counterparts in the central region. This suggests that households with HIV positive members may require government assistance differently across the country as the virus has varying impact depending on the social-economic set up in the community.

\subsection{HIV Infected Status and Human Capital Investment}

Table 3 presents marginal effects from the empirical model regarding the school enrolment of the children from HIV infected households and the results reinforce the expectation of the variables in the model. Most of the variables are statistically significant at the conventional level. In general, the empirical results regarding the children enrolment model are consistent with existing findings. Interpretation of the marginal probabilities makes more sense (Long, 1997) because "the partial derivative cannot be interpreted as the change in the expected count for a unit change" in an independent variable.

First, our empirical results on the effect of having an HIV infected household member on school enrolment of children in Uganda reveal interesting findings. Having HIV infected parents have a positive effect on overall enrolment of children in the HIV infected household. A child having both HIV infected parents has a large and significant positive effect of 0.128 to 0.214 percentage points on school enrolment. In addition, the share of children attending school shows a similar increase if the parents perceive to have a high risk of contracting the virus. Hence, the results strongly suggest that household heads anticipate their health risks by making sure that their children receive education. Basically, this means that parent admire to leave behind their children when are doing well and can be able to look after themselves beyond household wealth status, hence they continue to 
contribute to their education even after contacting the virus.

In regard to the existing marital status in HIV infected household, the results indicate that an HIV infected monogamous household increases the likelihood of children enrolment in school by a factor ranging between 0.021 to 0.0.082 units holding other variables constant at their mean. In addition, an HIV infected polygamous household decreases the likelihood of children enrolment in school by a factor of 0.002 units holding other variables constant at their mean. Also our results reveal that an HIV infected household with separated and divorced parents or divorced decreases the likelihood of children enrolment in school by a factor ranging between 0.004 and 0.013 units, holding other variables constant at their mean.

In line with expectations, our estimated results reveal that HIV infected parents and better-educated heads are more likely to send their children to school. The significant asset indicator shows that school attendance is higher among children from the wealthier households even when they are HIV infected. Furthermore, our empirical estimates reveal that mothers with primary, secondary education and postsecondary education compared to counterparts with no education in HIV infected households' increases the probability of children's school enrolment by $0.086-0.627 \%$. Additionally, father with primary, secondary education and postsecondary education, compared to counterparts with no education in HIV infected households increases the probability of children's school enrolment by $0.028-0.263$.

Table 3.The effect of household HIV Infection status on children's school enrolment

\begin{tabular}{|c|c|c|c|c|c|c|}
\hline \multirow{2}{*}{$\begin{array}{l}\text { Variables } \\
\text { Household HIV infectior }\end{array}$} & \multicolumn{2}{|c|}{ Model 1} & \multicolumn{2}{|c|}{ Model 2} & \multicolumn{2}{|c|}{ Model 3} \\
\hline & & & & & & \\
\hline Household head & $0.128 * *$ & $(0.008)$ & $0.149 * * *$ & $(0.000)$ & $0.214 * *$ & $(0.009)$ \\
\hline Household member & $-0.022 * *$ & $(0.005)$ & $-0.014 * * *$ & $(0.000)$ & $-0.011 * *$ & $(0.004)$ \\
\hline No HIV perception (d) & $0.223 * *$ & $(0.008)$ & $0.044 * *$ & $(0.007)$ & $0.048 * *$ & $(0.030)$ \\
\hline \multicolumn{7}{|l|}{ Marital status: } \\
\hline Monogamous marriage & $0.042 * * *$ & $(0.000)$ & $0.082 * *$ & $(0.008)$ & $0.021 *$ & $(0.010)$ \\
\hline Polygamous marriage & 0.061 & $(0.414)$ & $0.002 *$ & $(0.028)$ & -0.023 & $(0.418)$ \\
\hline Divorced/separated & $-0.004 * * *$ & $(0.000)$ & 0.022 & $(0.540)$ & $-0.013 * *$ & $(0.007)$ \\
\hline Widowed/widower & -0.049 & $(0.208)$ & 0.022 & $(0.423)$ & $-0.014 *$ & $(0.023)$ \\
\hline \multicolumn{7}{|c|}{ Mother's education: No education(RC) } \\
\hline Primary & 0.023 & $(0.446)$ & 0.213 & $(0.212)$ & -0.002 & $(0.739)$ \\
\hline Secondary & $0.086^{* *}$ & $(0.006)$ & $0.083^{*}$ & $(0.010)$ & $0.094 * * *$ & $(0.000)$ \\
\hline Postsecondary & $0.627 * * *$ & $(0.001)$ & $0.324 * * *$ & $(0.000)$ & $0.321 * * *$ & $(0.000)$ \\
\hline \multicolumn{7}{|c|}{ Father's education: No education(RC) } \\
\hline Primary & -0.026 & $(0.668)$ & 0.420 & $(0.374)$ & $0.028 *$ & $(0.003)$ \\
\hline Secondary & $0.043^{*}$ & $(0.039)$ & $0.022 * *$ & $(0.008)$ & $0.089 *$ & $(0.012)$ \\
\hline Postsecondary & $0.212 * *$ & $(0.008)$ & $0.144 *$ & $(0.022)$ & $0.263 * *$ & $(0.009)$ \\
\hline Log of child age & $0.236^{* * *}$ & $(0.000)$ & $0.124 *$ & $(0.070)$ & $0.046^{* *}$ & $(0.005)$ \\
\hline Log of age child squared & $-0.047 * * *$ & $(0.000)$ & $-0.084 * *$ & $(0.002)$ & $-0.107 * * *$ & $(0.000)$ \\
\hline Wealth status: & - & & - & & - & \\
\hline Household income & $0.225 * * *$ & $(0.000)$ & $0.327 * * *$ & $(0.000)$ & $0.643 * * *$ & $(0.000)$ \\
\hline Log of household asset & $0.028 * *$ & $(0.001)$ & 0.147 & $(0.642)$ & - & \\
\hline Health expenses & - & & $-0.244 *$ & $(0.029)$ & $-0.183^{* * *}$ & $(0.000)$ \\
\hline Distance to school & - & & $-0.140^{*}$ & $(0.018)$ & $-0.133^{* * *}$ & $(0.001)$ \\
\hline \multicolumn{7}{|c|}{ Land tenure system: Free hold (RC) } \\
\hline Lease land & $0.033^{*}$ & $(0.018)$ & - & & $0.083 * * *$ & $(0.000)$ \\
\hline Mail land & $0.055^{* *}$ & $(0.009)$ & - & & $0.022 *$ & $(0.010)$ \\
\hline Customary & -0.543 & $(0.245)$ & - & & $-0.045^{* *}$ & $(0.008)$ \\
\hline \multicolumn{7}{|l|}{ Regions: Central (RC) } \\
\hline Eastern & & & & & $0.022 * *$ & $(0.003)$ \\
\hline Northern & & & & & -0.061 & $(0.164)$ \\
\hline Western & & & & & $0.044^{* *}$ & $(0.007)$ \\
\hline No. of observation & \multicolumn{2}{|c|}{12084} & \multicolumn{2}{|c|}{3163} & \multicolumn{2}{|c|}{742} \\
\hline Likelihood ratio & \multicolumn{2}{|c|}{-7014} & \multicolumn{2}{|c|}{-1826} & \multicolumn{2}{|c|}{-404} \\
\hline$x^{2}$ & \multicolumn{2}{|c|}{0.80} & \multicolumn{2}{|c|}{0.64} & \multicolumn{2}{|c|}{0.77} \\
\hline
\end{tabular}

The P-values are given in parenthesis $(* \mathrm{p}<0.1$, ** $\mathrm{p}<0.05$, *** $\mathrm{p}<0.01)$. 
In addition, we include age and age squared in our empirical estimation on the impact of HIV infection and AIDS of the parents on human capital investment. Most interestingly, age of the children in HIV positive households increases the probability of children's school enrolment between 0.046 and 0.236 basis points in the Ugandan communities, other factor being equal. However, age squared of the HIV positive households is negatively related with schooling, as are his/her educational level and the household size controlling for the number of children.

Furthermore, our results indicate significance of total household income and assets on children schooling. The coefficients on the income variable for HIV infected status households are sizeable, positive, and statistically significant at the conventional levels. The estimated results indicate that the a unit increase in the household's income level will increase school enrolment by between 0.225 and 0.0 .643 percent if the parents are HIV infected compared to their counterparts, other factor remaining constant. The coefficient on the value of the household assets indicates that school enrolment increases by about 0.028 percentage points, holding all other factors at their mean.

Furthermore, our results indicate significance of land ownership by the HIV infected household on children's school enrolment. When an HIV infected household's land ownership is on a lease basis compared to counterparts that own free hold, this reduces the probability of the school enrolment of children increases by $7 \%$, keeping all other factors at their mean. In addition, if HIV infected household owns land based on mail land tenure system and customary, this decreases the probability of school enrolment of children overall by 4 percentage. In addition, the coefficient of log of land is not significant for school enrolment. It may be that wealth effect and substitution effect cancel each other out or that land holding is not an important determinant for school enrolment as children rarely work on the farm and the wealth effect is controlled well by the log of wealth variable.

Also analysis of the effect of employment status of HIV infected household reveals interesting results on the school enrolment of children. First, an HIV infected parent employed permanently privately compared to counterparts employed by government, increases the probability of the school enrolment of the children by 7 percentage among the HIV infected Ugandan communities. Secondly, a self-employed HIV infected household in business compared to counterparts that own free hold, this reduces probability of the school enrolment of left behind children by 7\% among the HIV infected Ugandan communities. However, an HIV infected parent that work in an informal sector compared to counterparts that own free hold, this reduces probability of the school enrolment of children by 7 percentage. This finding has strong implication on the decision of the parent on the education of their children as depending on the nature of job does; the likely consequences to the family are different.

Also from the model estimation, we note that the regional location of the HIV infected household's has significant effect on the school enrolment of the children in the households. Being from an HIV infected household and from the eastern region compared to those from the central region increases the probability of being enrolled in school by 0.022 , other factors being constant. In addition, being from an HIV infected household and from the north has no significant effect on school enrolment though the estimated coefficient is negative. However, a child being from the western and from an HIV infected status household will increase the probability of school enrolment by 0.044 basis points, other factors being constant. Therefore, these results further confirm the parents' interest in human capital investment irrespective of the HIV infection.

\section{Concluding Remarks}

This paper contributes to a better understanding of how individuals respond in anticipation of the HIV epidemic. We study the micro-economic impact of infection and perceived risk of HIV infection on saving behavior and human capital investment. This study has explored the effects of HIV and AIDS on household assets accumulation in Uganda, which may affect the size, rate of growth and productivity of the country's human capital stock and overall economic growth and development of the country. Therefore, the results of this study have been interpreted as "quantity effect" due to the influence of AIDS on the household's ability to accumulate assets. basically, the reduction in household assets and expected lower welfare implied by expected shorter life spans and reduced lifetime when the household bread winner is the one affected by HIV and AIDS act as a disincentive for the household heads to rationally choose to invest less in child intellectual human capital which affect their intergenerational mobility of income thus children tend to inherit their unfortunate conditions that they may continue to live in poverty. Thus, it is extremely important to understand the volatile effects of HIV and AIDS on households' capacity to generate assets.

First, the study findings indicate that epidemic threatens to sap away the saving and physical capital assets of 
households in the country, thereby reducing the productivity of workers who rely on physical capital to make use of their skills. The implication of this is that the depletion of household savings and assets implies a fall in household productivity, which not only has a strong bearing at household incomes, but has fiscal implications in terms of government tax revenue and fiscal expenditures to provide health services, education and poverty reduction as per the millennium development goals. Also, HIV and AIDS epidemic shorten the time horizon and increases the opportunity cost of household members' time, thus making investment in schooling less attractive. The results further show that the epidemic also threatens to erode the already existing human capital stock, as death of many of the country's most skilled workers reduces the average productivity of those left behind.

Our results provide a number of policy implications. First, the findings suggest that education in general has a profound intergenerational effect and thus deserves more attention from all stakeholders (parents, local community, NGOs and government). Wealth variables measured in terms of poor and non-poor households indicates that poverty has a significant negative and large effect on children's enrolment in schools for HIV infected households. This indicates that any policy that targets raising school enrolment beside the current UPE programme will have a significant contribution to school enrolment. Also policy makers should consider making the aid to be gender specific to gain effectiveness.

Secondly, mitigating the spread and the consequences of HIV and AIDS requires a coordinated approach involving agencies responsible for social and economic development to fully be involved. It is critical that policy makers anticipate the changes that HIV and AIDS will bring to the household livelihood, and proactively respond through the development of policies and programmes that factor in these projected impacts of the disease. Because many policies and programmes take years to implement and provide tangible results with a time lag after implementation, there is urgency to put in place an appropriate set of public investments and programmes that can cushion the blow by the time the long-wave impacts of AIDS are in full force, rather than respond reactively after crises caused by structural changes in the economy have already manifested.

One of the most important ways in which household income-asset policy can contribute to reducing the spread and consequences of AIDS is to contribute effectively to poverty reduction. Moreover, raising households' and communities' living standards over the long-run -through productivity-enhancing investments in labour saving technology generation and diffusion, improved household savings systems, basic education, infrastructure, and governance will improve their ability to withstand the social and economic stresses caused by the disease. Many of the household developmental policies and investments are critically important regardless of whether HIV and AIDS had become a major development challenge or not. But the onset of the epidemic makes labour saving technologies/productivity and household income growth all the more critical, especially if poverty exacerbates the spread of the disease, as is increasingly believed. Therefore, greater focus on productivity-enhancing investments policy measures provide a critical part of the effective response to the HIV and AIDS epidemic, and the extent to which progress is order to greatly influence living standards in these hardest-hit households.

In summary, the effects of the HIV epidemic on the accumulation of households' assets and productivity of human capital in Uganda are likely to go beyond those explored here. For example, to the extent government reorient its fiscal priorities to health spending, to care for those already infected and dying, education systems may find themselves starve for funding. Furthermore, the orphaning of thousands of children across the country may be expected to leave communities unable to rear children with the traditional level of care or attention. The analysis has implications for expected growth in the country, and thus for fiscal expectation and sustainability as for any worst hit country by the AIDS epidemic.

\section{References}

Ainsworth, M., \& Deon, F. (2001). Are Orphans Less Likely to be enrolled in School? Evidence from 25 DHSs. World Bank Policy Research Working Paper, Washington, DC (2001).

Arndt, \& Jefrey, D. L. (2001). The HIV/AIDS Pandemic in South Africa: Sectoral Impacts and Unemployment. Journal of International Development, 13(4), 427-49.

Bechu, N. (1998). The Impact of AIDS on the Economy of Families in Cote d'Ivoire: Changes in Consumption Among AIDS-Affected Households. In M. Aisworth et al. (Eds.), Confronting AIDS: Evidence from the Developing World. Brussels: European Commission.

Bell, C., Devarajan, S., \& Gersbach, H. (2003). The Long-Run Economic Costs of AIDS: Theory and Application to South Africa. World Bank Working Paper 3152, World Bank, Washington.

Caldwell, J. C. (2000). Rethinking the African AIDS Epidemic. Population and Development Review, 26(1), 117-135. http://dx.doi.org/10.1111/j.1728-4457.2000.00117.x 
David, E., Bloom, A. M., Lene, C., ... Gunatillake, T. (1997). Socioeconomic dimensions of AIDS in Sri Lanka in The Economics of HIV and AIDS. In D. E. Bloom, \& P. Godwin. (Eds.), The Case of South and Southeast Asia. New Delhi: Oxford University Press.

Dollar, D., \& Kray, A. (2000). Growth is Good for the Poor. World Bank, Working Paper, March 2000.

FAO. (2004). Protecting women's property and land rights to protect families in AIDS-affected communities. FAO Newsroom 09-03-2004.

Government of Uganda. (2003). The Impact of HIV/AIDS on Agricultural Production and Main streaming HIV/AIDS into Agricultural Extension in Uganda. Kampala: Ministry of Agriculture, Animal Industry and Fisheries.

ILO. (2000). HIVIAIDS: A threat to decent work, productivity and development. Geneva: ILO.

Ministry of Health. (2004/05). National HIV Sero and Behavioural Survey (NHSBS).

Morgan, D.(2002). HIV infections in rural Africa: Is There a Difference in Median Time to AIDS and Survival Compared with That in Industrialised Countries? AIDS, 16(4), 59-604. http://dx.doi.org/10.1097/00002030-200203080-00011

Opiyo, P. (2001). HIV/AIDS, Gender and Livelihood in Siaya District, Kenya: An Analysis of AIDS Impact on Rural Households. MS. Thesis. Wageningen University.

Uganda Bureau of Statistics. (2010). Uganda National Household Survey 2009/2010.

UNAIDS. (2002). Report on the Global HIV/AIDS Epidemic. UNAIDS, June 2002.

UNAIDS. (2015). Fact Sheet 2015 UNAIDS.

UNAIDS/WHO. (2004). Report on the Global AIDS Epidemic. Geneva's UNAIDS.

WHO. (2006). Progress on Global Access to HIV Antiretroviral Therapy. A Report on ' 3 by 5' and Beyond", March 2006. World Health Organization/Joint United Nations Porgramme on HIV/AIDS, Geneva.

WHO/UNAIDS. (2001). AIDS Epidemic Update, December 2001.

World Bank. (1997). Confronting AIDS: Public Priorities in a Global Pandemic. New York: Oxford University Press.

Yamano, T., \& Jayne, T. (2004). Measuring the Impacts of Working Age Adult Mortality among Small-Scale Farm Households in Kenya. World Development, 32(1), January. http://dx.doi.org/10.1016/j.worlddev.2003.07.004

\section{Copyrights}

Copyright for this article is retained by the author(s), with first publication rights granted to the journal.

This is an open-access article distributed under the terms and conditions of the Creative Commons Attribution license (http://creativecommons.org/licenses/by/3.0/). 